HETEROCYCLES, Vol. 97, No. 1, 2018, pp. 1 - 3. ๑ 2018 The Japan Institute of Heterocyclic Chemistry DOI: 10.3987/COM-18-S(T)Foreword_1

\title{
PREFACE TO HETEROCYCLES ISSUE HONORING THE 70TH BIRTHDAY OF PROFESSOR DR. KIYOSHI TOMIOKA
}

It is my great honor to write the foreword to the Special Issue of HETEROCYCLES on the occasion of the 70th birthday (Koki, Japanese traditional celebration of long life) of Professor Kiyoshi Tomioka.

Professor Kiyoshi Tomioka was born in 1948 in Tokyo, Japan. When he was an undergraduate student at the University of Tokyo, he loved mathematics and philosophy. However, he entered the Faculty of Pharmaceutical Sciences in order to study a diverse range of topics in science. The direction of his career was influenced by Professor Shun-ichi Yamada, who led him to organic chemistry, especially asymmetric synthesis. He received his Ph.D. from the University of Tokyo in 1976 under the direction of Prof. S. Yamada. During his Ph.D. research, he achieved the biogenetic asymmetric synthesis of optically active Amaryllidaceae alkaloids, $(+)$-maritidine, $(+)$-galanthamine, and (-)-galanthamine from optically active amino acids. He then joined Prof. A. I. Meyers' laboratory at Colorado State University as postdoctoral fellow in 1976, because he wanted to take on the challenge of total synthesis of large molecules. During his postdoctoral fellowship, he contributed to the total synthesis of the anti-tumor ansa-macrolide, maytansine, and became acquainted with Dr. Daniel L. Commins (later Professor at NCSU) as a colleague and Dr. Tamio Hayashi (later Professor at Kyoto University) as a "teacher of organometallics" to Dr. Tomioka. In 1978, he returned to Prof. Kenji Koga's laboratory at the University of Tokyo as Research Associate and was appointed as Associate Professor in 1983. During this period, he started research on asymmetric reactions utilizing chiral lactones, chiral enamines, and chiral ligands for several organometals such as lithium, magnesium, copper, and osmium.

In 1992, Professor Tomioka was promoted to Full Professor at Osaka University, at the Institute of Scientific and Industrial Research. In 1996, he moved to Kyoto University as a Professor of the Faculty and Graduate School of Pharmaceutical Sciences. During his work at Kyoto University, Professor Tomioka reported novel radical reactions initiated by organozinc and rhodium-catalyzed asymmetric reactions, in addition to asymmetric organolithium reactions and asymmetric total synthesis. In 2010 , he became Professor of the Faculty of Pharmaceutical Sciences at Doshisha Women's College of Liberal Arts, and Emeritus Professor at Kyoto University. Professor Tomioka will be retiring in 2018 when he reaches the retirement age of 70 .

The chemistry developed by Professor Tomioka has appeared in more than 300 publications, including original papers, reviews, accounts, and books. His achievement of asymmetric total syntheses of the 
medicinally important natural products-(-)-podorhizon, (+)-burseran, $(+)$-sesbanine, (+)-steganacin, (-)-bourbonene, (+)-ivalin, (-)-megaphone, (+)-spatol, (+)-sesbanimide, dolastatin 10, (+)-salsolidine, (-)-neplanocin, (+)-calonectrin, (-)-lycorine, (-)-kopsinine, etc.-are based on his own strategy of asymmetric reactions and the fundamental properties of the molecular structures. Chiral ligand-catalyzed asymmetric reactions of carboanions, which are distinct from transition metal-catalyzed asymmetric reactions, constitute one of the pioneering works in the field of asymmetric organocatalysts. The molecular design of chiral ligands with organometals, especially organolithium, is one of his representative outstanding achievements, in which $\mathrm{C}_{2}$-symmetric chiral diamines and diethers developed by him reveal a beautifully designed ligand. Professor Tomioka explained to us "The simpler the molecular design is, the greater will be its useful possibility." That is true! In this chemistry, highly enantioselective carbon-carbon bond formation reactions with carboanions such as organolithiums were accomplished by "asymmetric organocatalysts." For his achievement in organic chemistry, he received The Pharmaceutical Society of Japan Award for Young Scientists in 1984, The Research Foundation for Optically Active Compounds Award in 1991, and the Pharmaceutical Society

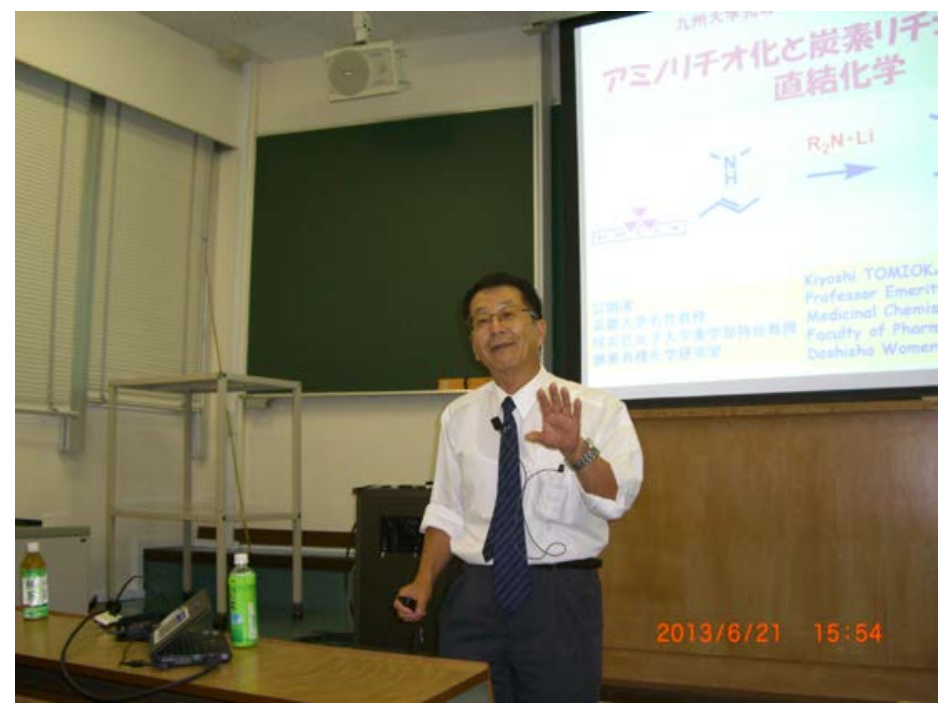
of Japan Award in 2003, and he was appointed as Fellow of The Royal Society of Chemistry in 2016. Aside from his achievements in science, Professor Tomioka has contributed to academic societies as Chairman of the organic chemistry division of the Pharmaceutical Society of Japan (2004-2007), Vice President of the Pharmaceutical Society of Japan (2011-2013), and one of the founding members of the Japanese Society of Process Chemistry (funded by Professor T. Shioiri) as Vice-President (2001-2010) and President (2010-2017). He has also been part of many editorial boards and served as editor, including Editor of Tetrahedron (2007-present). He served as the Dean of the Faculty and Graduate School of Pharmaceutical Sciences (2006-2007) at Kyoto University to ensure its management and growth.

When I was an undergraduate student (35 years ago!), I had the opportunity to talk about chemistry (I was too young to "discuss") with Professor Tomioka. I was so impressed by his intelligence and passions for chemistry, particularly creating molecules, that I decided to pursue studies on organic chemistry under his direction (he was Associate Professor then). As a graduate student, I was trained from the basics to advanced levels of not only organic chemistry but also fundamental sciences under his strict direction. I 
believe that this is the most precious and important experience in my life, which led me (as well as my colleagues at that time) to the academic course.

When Professor Tomioka moved to Doshisha Women's College of Liberal Arts after retiring from Kyoto University, he said to me "Dreams come true," which may mean that the education of women is becoming increasingly important to him as he has three daughters! Of course, Professor Tomioka is not now "a strict professor" but a kind and merry professor to his current college students. Professor Tomioka has maintained his youthfulness by surrounding himself with the enthusiasm and energy found at a college. The fact that he is an active golf player has also been important for maintaining his youthfulness. However, he has still been "a strict supervisor" for us (his former students) and gives serious but heart-warming advice and opinions, which encourage us greatly and are much appreciated.

The special issue of HETEROCYCLES is dedicated to Professor Kiyoshi Tomioka on the occasion of his 70th birthday (Koki). On behalf of Professor Tomioka's former and present students, I wish him a happy, healthy life.

\author{
Mitsuru Shindo \\ Institute for Materials Chemistry and Engineering, Kyushu University \\ Fukuoka, Japan
}

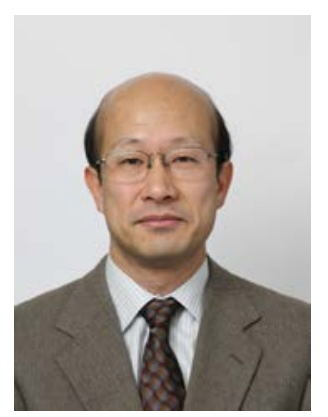

Mitsuru Shindo was born in Tokyo, Japan, in 1963. He graduated from the Faculty of Pharmaceutical Sciences, University of Tokyo, in 1986, and then entered the Graduate School of the University of Tokyo. He was appointed as Research Associate in Prof. Koga's group at the University of Tokyo in 1990 and received his $\mathrm{Ph}$. D. from the University of Tokyo under the supervision of Professors Kenji Koga and Kiyoshi Tomioka. After working with Professor R. A. Holton's group as a postdoctoral fellow for two years, he returned to the University of Tokyo, and was then promoted to Associate Professor at Tokushima University in 1996. After joining Kyushu University in 2005, he was appointed as Full Professor at the Institute for Materials Chemistry and Engineering at Kyushu University in 2010. His research interests include the development of new reactions as well as the design and synthesis of biologically useful compounds. 